\title{
SURVEI KELUARGA SEHAT DI DESA PENEGAH KECAMATAN PELAWAN
}

\author{
Tina Yuli Fatmawati \\ Prodi DIII Keperawatan STIKes Baiturrahim Jambi \\ Email:tinayulifatmawati@yahoo.com
}

\begin{abstract}
The movement of healthy living people is a choice in realizing a better degree of public health. The aim is to increase awareness in the community in preventing disease. Health problems that aries are the result of unhealthy living behaviors and poor environmental sanitation. This research is a descriptive research that is a study directed to describe or describe a situation within a community or society. The sample in this study were 277 Famillies in Penegah village with total sampling technique. The results is majority of mothers using family planning, mothers giving birth in health care facilities, babies receiving $100 \%$ complete immunization, the majority of mothers giving exclusive breastfeeding, The people not found pulmonary tuberculosis, 100\% of hypertensive patients checking periodically, no one suffering from mental disorders, the majority of families there are those who smoke, the majority of families use health insurance / BPJS, the coverage of monitoring for toddlers' growth is $100 \%$, the use of clean water sources and 100\% healthy latrines. It is expected that the Puskesmas will further encourage the independence of healthy life for individuals, families, groups and communities through community empowerment so that it becomes a healthy community.
\end{abstract}

Keywords : Healty life, Family

ABSTRAK
Gerakan Masyarakat Hidup Sehat (GERMAS) menjadi sebuah pilihan dalam
mewujudkan derajat kesehatan masyarakat yang lebih baik. Tujuannya
memunculkan kesadaran pada masyarakat dalam mencegah penyakit.
Permasalahan kesehatan yang timbul merupakan akibat perilaku hidup yang tidak
sehat dan sanitasi lingkungan yang buruk yang sebenarnya dapat dicegah bila
fokus pelayanan kesehatan diutamakan pada pelayanan kesehatan preventif dan
promotif. Penelitian ini merupakan penelitian deskriptif yaitu suatu penelitian
yang diarahkan untuk mediskripsikan atau menguraikan suatu keadaan didalam
suatu komunitas. Penelitian ini bertujuan untuk mengetahui gambaran Keluarga
sehat di desa Penegah Kec.Pelawan. Sampel dalam penelitian ini adalah Kepala
Keluarga di desa Penegah sebanyak 277 responden dengan teknik pengambilan
sampel Total Sampling. Hasil penelitian diketahui Berdasarkan hasil dari 12
indikator keluarga sehat, diperoleh mayoritas ibu menggunakan KB, ibu
melakukan persalinan di fasilitas pelayanan kesehatan, bayi mendapat imunisasi
lengkap 100\%, Mayoritas ibu memberikan ASI ekslusif, masyarakat tidak
ditemukan TB paru, 100\% penderita Hipertensi melakukan pengecekan berkala,
tidak ada yang menderita gangguan jiwa, mayoritas keluarga ada yang merokok,
mayoritas keluarga menggunakan jaminan kesehatan/BPJS, cakupan pemantauan
tumbuh kembang balita 100\%, penggunaaan sumber air bersih dan jamban sehat
100\%. Diharapkan bagi Puskesmas agar lebih mendorong kemandirian hidup 
sehat bagi individu, keluarga, kelompok dan masyarakat melalui pemberdayaan masyarakat, sehingga tercipta masyarakat sehat dan produktif.

Kata Kunci : Hidup sehat, Keluarga

\section{PENDAHULUAN}

Pembangunan kesehatan pada hakekatnya adalah upaya yang dilaksanakan oleh semua komponen bangsa Indonesia yang bertujuan untuk meningkatkan kesadaran, kemauan, dan kemampuan hidup sehat bagi setiap orang agar terwujud derajat kesehatan masyarakat yang setinggi-tingginya. Keberhasilan pembangunan kesehatan sangat ditentukan oleh kesinambungan antarupaya program dan sektor, serta esinambungan dengan upaya-upaya yang telah dilaksanakan dalam periode sebelumnya. Untuk mengatasi permasalahan kesehatan tersebut telah dilakukan berbagai upaya pendekatan program, misalkan dengan program peningkatan akses dan kualitas pelayanan kesehatan, program pemberdayaan masyarakat bidang kesehatan, program aksesibilitas serta mutu sediaan farmasi dan alat kesehatan, program penelitian dan pengembangan, program manajemen, regulasi dan sistem informasi kesehatan dan program kesehatan lainnya.( Indonesia, 2017)

Pembangunan kesehatan adalah meningkatnya kesadaran, kemauan, dan kemampuan hidup sehat bagi setiap orang agar peningkatan derajat kesehatan masyarakat yang setinggitingginya dapat terwujud. Hal itu berarti terciptanya masyarakat, bangsa, dan negara Indonesia yang penduduknya, di seluruh wilayah Republik Indonesia, hidup dengan perilaku dan dalam lingkungan sehat, memiliki kemampuan untuk menjangkau pelayanan kesehatan yang bermutu secara adil dan merata, serta memiliki derajat kesehatan yang setinggi-tingginya.

masyarakat erat kaitannya dengan perilaku dan lingkungan. Perbaikan lingkungan dan perubahan perilaku ke arah yang lebih sehat perlu dilakukan secara sistematis dan terencana oleh semua komponen bangsa. Gerakan Masyarakat Hidup Sehat (Germas) menjadi sebuah pilihan dalam mewujudkan derajat kesehatan masyarakat yang lebih baik. Tujuannya memunculkan kesadaran pada masyarakat dalam mencegah penyakit. Hasil penelitian menunjukkan ada hubungan antara kualitas sumber air minum $(\mathrm{p}=$ 0,008) dan pemanfaatan jamban keluarga $(p=0,005)$ dengan kejadian diare. (Pamusthi Wandansari \& Mitra Keluarga Semarang, 2013) Penggunaan Air Bersih dengan baik yaitu 47 orang $(83.9 \%)$, berdasarkan mencuci tangan dengan baik yaitu 32 orang (57.1\%), berdasarkan Membuang tinja dengan baik yaitu 17 orang $(30.4 \%)$. Tidak ada hubungan antara penggunaan air bersih dengan kejadian diare dengan nilai $\mathrm{p}$-value $=0,907$, ada hubungan mencuci tangan dengan kejadian diare pada balita dengan nilai $\mathrm{p}$-value $=0,006$. (Tina Yuli Fatmawati, Iin Indrawati, 2017)

Permasalahan kesehatan yang timbul merupakan akibat perilaku hidup yang tidak sehat dan sanitasi lingkungan yang buruk yang sebenarnya dapat dicegah bila fokus 
pelayanan kesehatan diutamakan pada pelayanan kesehatan preventif dan promotif. Kegiatan tersebut dapat dilakukan melalui upaya promosi kesehatan. Upaya promotif dan preventif dalam menumbuhkan dan mengembangkan kemandirian keluarga dan masyarakat untuk berperilaku hidup bersih dan sehat.

Berdasarkan fenomena dan data tersebut peneliti tertarik untuk melakukan penelitian yang berjudul "Gambaran Keluarga Sehat di Desa Penegah Kecamatan Pelawan, Kabupaten Sarolangun Jambi.

\section{METODE PENELITIAN}

Penelitian ini merupakan penelitian deskriptif yaitu suatu penelitian yang bertujuan untuk mediskripsikan atau menguraikan suatu keadaan didalam suatu komunitas atau masyarakat. Penelitian ini bertujuan untuk mengetahui gambaran Keluarga sehat di Kecamatan Pelawan .Adapun lokasi dalam penelitian ini bertempat di Desa Penegah. Sampel dalam penelitian ini adalah Kepala Keluarga di desa Penegah sebanyak 277 responden dengan teknik pengambilan sampel Total Sampling. Tehnik pengumpulan data diperoleh dari responden dengan wawancara menggunakan kuesioner. analisa data yang dilakukan adalah analisis univariat dimana analisis ini untuk menggambarkan distribusi dari variabel-variabel yang diteliti

\section{HASIL DAN PEMBAHASAN}

\section{AnalisaUnivariat}

Gambaran Keluarga yang mengikuti program KB
Berdasarkan hasil penelitian diketahui hasil distribusi frekuensi usia balita yang lebih jelasnya dapat dilihat pada tabel sebagai berikut :

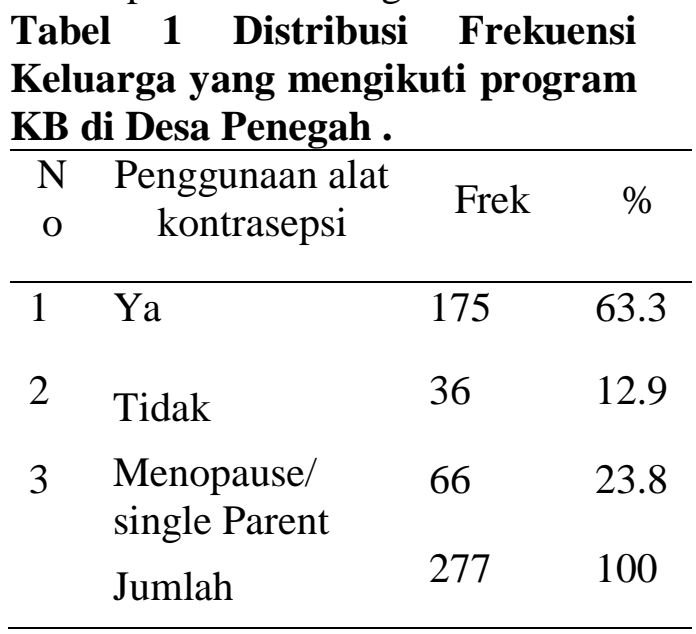

Berdasarkan data diatas dapat disimpulkan bahwa dari $277 \mathrm{kk}$, ibu yang menggunakan alat kontrasepsi 175 orang $(63.3 \%)$ dan yang tidak sebanyak 36 orang (12.9\%). Sedangakan 66 responden $(23.8 \%)$ karena menopause/single parent.

Dari $36 \mathrm{ibu}$, alasan terbanyak tidak menggunakan $\mathrm{KB}$ adalah ingin memiliki keturunan sebanyak 31 orang $(86,1 \%)$ dan alasan tidak nyaman sebanyak 5 orang $(13,8 \%)$.

$\mathrm{KB}$ adalah untuk membentuk keluarga kecil sesuai dengan kekuatan sosial - ekonomi suatu keluarga dengan cara mengatur kelahiran anak, agar diperoleh suatu keluarga bahagia dan sejahtera yang dapat memenuhi kebutuhan hidupnya (Mochtar, 2002) Dalam Supariasi, 2014. Untuk mewujudkan gerakan itu maka disarankan kepada pihak Puskesmas melakukan sosialisasi KB khususnya kepada responden yang belum mengikuti program $\mathrm{KB}$,sehingga program tersebut dapat tercapai. 
Gambaran Ibu yang melakukan persalinan di fasilitas kesehatan.

Berdasarkan hasil penelitian diketahui seluruh ibu menggunakan fasilitas persalinan di fasilitas pelayanan kesehatan seperti Bidan, Puskesmas dan RS.

Dapat disimpulkan bahwa masyarakat di desa Penegah sudah memahami pentingnya meningkatkan kesehatan terutama pada ibu dan bayi

Sebagaimana sasaran dari pembangunan kesehatan pada tahun 2025 adalah meningkatnya derajat kesehatan masyarakat, dengan indikator meningkatnya Umur Harapan Hidup, menurunnya Angka Kematian Bayi, menurunnya Angka Kematian Ibu, dan menurunnya prevalensi gizi kurang pada balita ndonesia. (Kementerian Kesehatan RI, 2016).

\section{Gambaran Bayi yang mendapat} imunisasi dasar lengkap.

Berdasarkan hasil penelitian diketahui dari 72 balita, seluruhnya mendapatkan imunisasi lengkap. Data diatas sudah sesuai dengan target yaitu $100 \%$ balita mendapat imunisasi dasar lengkap.

Orangtua merupakan kunci utama dalam pertumbuhan dan perkembangan balita. Untuk mewujudkannya orang tua harus selalu mengawasi, menjaga, memperhatikan khususnya pada peningkatan kesehatan. Salah satunya dengan pemahaman orangtua terhadap pentingnya imunisasi dasar pada balita. Kurangnya sosialisasi dari petugas kesehatan dapat menyebabkan masalah rendahnya pemahaman dan kepatuhan ibu dalam program imunisasi.

Gambaran Bayi yang mendapat ASI Ekslusif.
Berdasarkan hasil penelitian diketahui bahwa ibu yang sedang memberikan ASI saat ini berjumlah 16 orang dan yang memberikan ASI ekslusif sebanyak 12 orang (75\%) dan yang tidak memberikan ASI ekslusif sebanyak 4 orang (25\%).

Meksipun mayoritas ibu sudah memberikan ASI ekslusif, namun ada beberapa ibu yang masih belum memberikan ASI ekslusif. Hal ini harus mendapat perhatian khususnya pihak Puskesmas. Karena salah satu upaya dalam menurunkan AKB adalah dengan memberikan Air Susu Ibu (ASI) eksklusif. ASI adalah makanan alami pertama untuk bayi yang memberikan semua vitamin, mineral dan nutrisi yang diperlukan oleh bayi untuk pertumbuhan dalam enam bulan pertama dan tidak ada makanan atau cairan lain yang diperlukan. ASI memenuhi setengah atau lebih kebutuhan gizi anak pada tahun pertama hingga tahun kedua kehidupan (WHO, 2002 dalam Septiani, 2017).

Pada penelitian Septiani, 2017, tentang Faktor-Faktor yang Berhubungan dengan Pemberian ASI Eksklusif Oleh Ibu Menyusui, hasil yang diperoleh menyatakan bahwa Pemberian ASI eksklusif lebih banyak pada kelompok ibu dengan pengetahuan baik (72, 8\%) dibandingkan ibu dengan pengetahuan kurang. Untuk itu pentingnya edukasi pada ibu baik secara langsung maupun melalui media seperti poster, leaflet dan lainlain, sehingga pemahaman ibu tentang penting ASI dapat meningkat.

$\begin{array}{lrr}\text { Gambaran } & \text { Balita } & \text { yang } \\ \text { mrndapatkan } & \text { pemantauan } \\ \text { Pertumbuhan. } & \end{array}$


Jumlah balita di Desa Penegah adalah Sebanyak 72 orang balita. Dan semuanya mendapatkan Pemantauan pertumbuhan di Posyandu terdekat.

Target pada 2025 pemerintah antara lain menargetkan menurunkan balita Stunting sebesar 40\%, menurunkan balita kurus (wasting) sekitar 5\%, menurunkan bayi dengan berat badan lahir rendah (BBLR) $30 \%$, tidak ada kenaikan persentase anak gizi lebih, menurunkan wanita usia subur (WUS) anemia 50\%, dan meningkatkan ASI eksklusif paling kurang 50\%.(Jurnal Keluarga, 2018). Dengan Upaya Pemantauan Tumbuh Kembang balita setiap bulan hingga usia Lima Tahun diharapkan target tersebut dapat segera tercapai.

\section{Gambaran penderita Tuberkulosis} di desa Penegah.

Berdasarkan hasil penelitian diketahui Peneliti tidak menemukan penderita dengan TB Paru. Hal ini cukup baik namun demikian Masyarakat perlu diberikan edukasi tentang bahaya TBC .

Gambaran penderita Hipertensi di desa Penegah

Berdasarkan hasil penelitian disimpulkan bahwa riwayat penyakit lansia yang paling banyak adalah rematik sebanyak 62 orang $(81,5 \%)$ dan paling sedikit adalah tb paru sebayak 2 orang (2,6\%). Sedangkan penderita hipertensi hanya 5 orang. Semuanya selalu melakukan pengecekkan tekanan darah ke Puskesmas terdekat.

Salah satu penyakit tidak menular yang cukup penting dalam Pendekatan Keluarga adalah hipertensi (tekanan darah tinggi). Prevalensi hipertensi pada orang dewasa menurut Riskesdas tahun
2013 adalah 25,8\% atau sama dengan 42,1 juta jiwa. Dari sejumlah itu baru $36,8 \%$ yang telah kontak dengan petugas kesehatan, sementara sisanya sekitar $2 / 3$ tidak tahu kalau dirinya menderita hipertensi. Hal ini menunjukkan bahwa bila tidak menggunakan pendekatan keluarga, $2 / 3$ bagian atau sekitar 28 juta penderita hipertensi tidak akan tertangani (Kemenkes RI, 2016).

Sejalan dengan penelitian Avicena tentang Analisis capaian indikator keluarga sehata dengan menggunakan metode community diagnosis, bahwa cakupan pengobatan penderita hipertensi berjumlah $100 \%$ ( 6 penderita)

\section{Gambaran penderita gangguan jiwa sehat di desa Penegah.}

Berdasarkan hasil penelitian diketahui bahwa tidak ada Keluarga yang memiliki anggota keluarga mengalami gangguan jiwa.

Gambaran Perokok dalam
keluarga di desa Penegah

Berdasarkan hasil penelitian diketahui distribusi frekuensi adanya perokok dapat dilihat pada tabel sebagai berikut :

Tabel 2 Distribusi Frekuensi Perokok dalam keluarga di Kel. Kenali Asam Bawah

\begin{tabular}{llll}
\hline $\mathrm{N}$ & Adanya & Frekuens & \\
$\mathrm{O}$ & Perokok & $\mathrm{i}$ & $\%$ \\
\hline \multicolumn{4}{l}{ Ada } \\
1 & Perokok & 207 & 74.7 \\
& Tidak Ada & & \\
2 & Perokok & 70 & 25.3 \\
Jumlah & 277 & 100 \\
\hline
\end{tabular}

Berdasarkan data diatas dapat disimpulkan bahwa anggota keluarga yang merokok sebanyak 207 $\operatorname{rumah}(74.7 \%)$ dan yang tidak 
merokok sebanyak 70 rumah $(25.3$ $\%)$.

Rokok merupakan benda beracun yang memberi efek yang sangat membahayakan pada perokok ataupun perokok pasif, terutama pada balita yang tidak sengaja terkontak asap rokok. Nikotin dengan ribuan bahaya beracun asap rokok lainnya masuk ke saluran pernapasan anak yang dapat menyebabkan Infeksi pada saluran pernapasan (Hidayat, 2005 dalam Trisnawati 2012).

Rokok juga menyumbang terjadinya ISPA khusunya pada Balita. Penelitian penulis sebelumnya tentang Analisis Karakteristik Ibu, Pengetahuan dan Kebiasaan Merokok dengan Kejadian ISPA pada Balita di Kelurahan Kenali Asam Bawah, hasil yang diperoleh Dari uji statistik didapat $p$-value 0,000 ( $p$-value $<0,05)$ yang berarti dapat disimpulkan terdapat hubungan antara adanya perokok dengan kejadian ISPA pada balita di Kel. Kenali Asam Bawah dengan nilai OR 19.067 (6.170-58.919), artinya yang perokok mempunyai peluang 19.06 kali untuk mengalami kejadian ISPA pada balita. (Fatmawati, 2018)

Asap rokok dapat mengganggu saluran pernafasan bahkan meningkatkan penyakit infeksi pernafasan termasuk ISPA, terutama pada kelompok umur balita yang memiliki daya tahan tubuh masih lemah, sehingga bila ada paparan asap, maka balita lebih cepat terganggu sistem pernafasannya seperti ISPA. Oleh karena itu Pentingnya pendidikan kesehatan tentang bahaya rokok baik pada remaja pria dan orangtua (ayah) terus selalu ditingkatkan agar tercipta derajat kesehatan yang optimal pada keluarga.

\section{Gambaran keluarga yang memiliki JKN desa Penegah.}

Berdasarkan hasil penelitian diketahui hasil distribusi frekuensi keluarga yang memiliki JKN yang lebih jelasnya dapat dilihat pada tabel sebagai berikut :

Tabel 3 Distribusi Frekuensi keluarga yang memiliki JKN

\begin{tabular}{llll}
\hline No & $\begin{array}{c}\text { Kepemilikan } \\
\text { /BPJS }\end{array}$ & Frekuensi & $\%$ \\
\hline 1 & ya & 265 & 95.6 \\
2 & tidak & 12 & 4.3 \\
& Jumlah & 277 & 100 \\
\hline
\end{tabular}

Berdasarkan data diatas dapat disimpulkan bahwa yang memiliki JKN sebanyak 265 rumah $(95,6 \%)$ da yang tidak memiliki JKN sebanyak 12 rumah $(4.3 \%)$.

Masyarakat yang tidak memiliki JKN/BPJS setelah ditanyakan dikarenakan belum mengurus karena repot. BPJS kesehatan merupakan Badan Usaha Milik Negara yang berubah menjadi Badan Hukum Publik yang ditugaskan khusus oleh pemerintah untuk menyelenggarakan jaminan kesehatan bagi seluruh rakyat Indonesia. Program ini melayani berbagai lapisan dari kalangan masyarakat. BPJS Kesehatan ditujukan untuk memberikan proteksi agar seluruh lapisan masyarakat mendapatkan akses kesehatan secara merata. Tujuan program BPJS Kesehatan adalah mewujudkan terselenggaranya pemberian jaminan kesehatan yang layak bagi setiap peserta sebagai pemenuhan kebutuhan dasar hidup penduduk Indonesia.

Sosialisasi merupakan langkah awal yang menentukan keberhasilan program dalam mencapai tujuan, 
oleh karena itu sosialisasi program harus dilakukan agar semua informasi tersampaikan dan dapat dipahami oleh seluruh masyarakat agar tujuan yang direncanakan bisa tercapai dengan baik.

Gambaran penggunaan sarana air bersih di desa Penegah.

Berdasarkan hasil penelitian diketahui hasil distribusi frekuensi penggunaan air bersih dapat dilihat pada tabel sebagai berikut :

\section{Tabel 4 Distribusi Frekuensi penggunaan sarana air bersih}

\begin{tabular}{|c|c|c|c|}
\hline No & $\begin{array}{l}\text { Penggunaaan } \\
\text { air bersih }\end{array}$ & Frekuensi & $\%$ \\
\hline 1 & Sumur & 175 & 63.1 \\
\hline 2 & PAM/PDAM & 102 & 36.8 \\
\hline \multirow[t]{2}{*}{3} & Sungai & 0 & 0 \\
\hline & Jumlah & 277 & 100 \\
\hline \multicolumn{4}{|c|}{$\begin{array}{l}\text { disimpulkan bahwa dari } 277 \\
\text { responden yang memiliki sarana air } \\
\text { bersih yaitu sumur sebanyak } 175 \\
(63,1 \% \text { ) dan yang menggunakan } \\
\text { PAM } 102(36,8 \%) \text {. }\end{array}$} \\
\hline
\end{tabular}

Hasil penelitian ini memperlihatkan bahwa mayoritas Kepala keluarga menggunakan sarana air bersih, namun demikian, KK yang sumurnya berwarna sebanyak $15 \quad(5,4 \%)$ dan jarak sumur dengan septiktank $<10 \mathrm{~m}$ sebanyak $82(29,6 \%)$ dan terdapat sumber pencemaran lingkungan sebanyak 56,3\%. Hal ini dapat menyumbang terjadinya pencemaran air yang berdampak buruk terhadap kesehatan seperti tingginya angka kejadian diare. Kita ketahui salah satu faktor lingkungan yang dapat mempengaruhi kejadian diare pada balita adalah penggunaan air bersih dan jamban sehat. Air yang tercemar mengandung banyak bakteri, salah satunya adalah Escerichia coli yang merupakan bakteri penyebab diare. Sumber air bersih merupakan salah satu sarana sanitasi yang berhubungan erat dengan penyakit diare.

Gambaran penggunaan jamban sehat di desa Penegah.

Berdasarkan hasil penelitian diketahui hasil distribusi frekuensi penggunaan jamban sehat hasil yang diperoleh bahwa semua rumah memiliki jamban/ WC dengan jenis leher angsa. Artinya semua KK menggunakan jamban sehat.

Upaya yang dilakukan Masyarakat desa Penegah telah menyumbang tercapainya Program 1000 Hari Pertama Kehidupan meliputi intervensi sensitif berupa penyediaan akses dan ketersediaan air bersih serta sarana sanitasi (jamban sehat) di keluarga.( Direktorat Advokasi dan KIE, 2018). Kepemilikan dan penggunaan jamban sehat merupakan salah satu indikator program Perilaku Hidup Bersih dan Sehat (PHBS) ditatanan rumah tangga. Salah satu kegiatan pokok puskesmas adalah kesehatan lingkungan dan penyuluhan kesehatan masyarakat, dimana pelaksanaan kegiatan pokok tersebut diarahkan kepada khsusunya keluarga agar tercipta perilaku hidup bersih dan sehat..

\section{SIMPULAN}

Berdasarkan hasil dari 12 indikator keluarga sehat, diperoleh mayoritas ibu menggunakan KB, ibu melakukan persalinan di fasilitas pelayanan kesehatan, bayi mendapat imunisasi lengkap 100\%, Mayoritas ibu memberikan ASI ekslusif, 
masyarakat tidak ditemukan TB paru, penderita Hipertensi melakukan pengecekan berkala, Masyarakat desa Penegah tidak ada yang menderita gangguan jiwa, mayoritas keluarga ada yang merokok, mayoritas keluarga menggunakan jaminan kesehatan/BPJS, cakupan pemantauan tumbuh kembang balita $100 \%$, penggunaaan sumber air bersih dan jamban sehat $100 \%$.

\section{SARAN}

Meskipun penelitian ini menggambarkan hasil yang cukup baik, namun demikian kepada pihak Puskesmas setempat agar tetap selalu mendorong kemandirian hidup sehat bagi individu, keluarga, kelompok, dan masyarakat melalui pemberdayaan masyarakat dan upaya promosi kesehatan, bersama masyarakat dalam merencanakan dan melakukan pemecahan masalah dengan memanfaatkan potensi yang ada di masyarakat dengan demikian akan tercipta masyarakat yang sehat.

\section{DAFTAR PUSTAKA}

1. Amrin,Madolan https://www.mitrakesmas.com/2 017/05/12-indikator-keluargasehat-serta.html, diakses Desember 2017

2. Andarmoyo, Sulistyo, 2012. Keperawatan Keluarga, Konsep teori, proses dan praktik keperawatan, Graha Ilmu,Yogyakarta

3. Arikunto, S.2010.Prosedur Penelitian Suatu Pendekatan Praktik.Rineka Cipta.Jakarta.

4. Avicena SM, 2017.Analisis capaian indikator keluarga sehat dengan menggunakan metode community diagnosis, $h$ ttp://jurnal.bhmm.ac.id/index.p hp/jurkes/article/download/17/20 http://jurnal.bhmm.ac.id/index.p hp/jurkes/article/download/17/20

5. Direktorat Advokasi dan KIE, 2018, Jurnal Keluarga, Jakarta.

6. Hidayat, A.A. 2007. Riset Keperawatan dan Tehnik Penulisan Ilmiah. Salemba Medika. Jakarta

7. Indonesia,2016. Pedoman Umum Program Indonesia Sehat dengan Pendekatan Keluarga.Jakarta: Kementerian Kesehatan RI

8. Kemenkes RI, 2017, Gerakan Masyarakat Hidup Sehat GERMAS, Jakarta https://www.researchgate.net/pu blication/307445716_Kemandiri an_Keluarga_Berencana_KB_p ada_Pasangan_Usia_Subur_di_ Kota_Yogyakarta [accessed Juli 2018]

9. Fatmawati, T. Y. (2017). Pengetahuan, Sikap, Dan Perilaku Siswa-Siswi Tentang Personal Hygiene Di Sd Negeri Kota Jambi Knowledge, Attitude And Behavior Students About Hygiene Personal In Sdn Kota Jambi. Scientia Journal, 6(1). Retrieved from http://ejournal.unaja.ac.id/index.ph $\mathrm{p}$ ?journal $=$ SCJ $\&$ page $=$ article $\&$ op $=$ view\&path $\% 5 \mathrm{~B} \% 5 \mathrm{D}=52 \&$ path $\% 5$ $\mathrm{B} \% 5 \mathrm{D}=43$

10.Fatmawati, T. Y. (2017). Analisis Karakteristik Ibu, Pengetahuan dan Kebiasaan Merokok dengan Kejadian ISPA pada Balita di Kelurahan Kenali Asam Bawah, Jurnal Ilmiah Universitas Batanghari Jambi Vol.18 No.3 Tahun 2018 , http://ji.unbari.ac.id/index.php/ilmiah/a rticle/view/516/459 